\title{
Метакультурные константы и связи старообрядцев Тувы (на материале путевых записей археографической экспедиции Н. Н. Покровского 1967 г.)
}

\author{
Ольга И. Валентинова \\ Российский университет дружбы народов, Российская Федерация, \\ Олег В. Никитин
}

Петрозаводский государственный университет, Российская Федерация

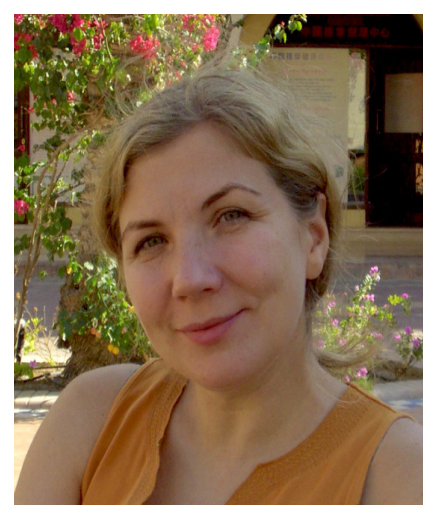

В статье анализируются метакультурные константы старообрядцев Тувы, отраженные в материалах археографической экспедиции Н. Н. Покровского (1967). Авторы рассматривают полевые записи ученых как оригинальный памятник письменной культуры того времени и как источник персонифицированной информации о численности, составе, образовании, религиозных обрядах и духовных ценностях, обиходных устоях и рече-поведенческих тактиках древлеправославного населения.

Исследуемые документы раскрывают специфику взаимоотношений жителей скитов с мирскими людьми. В статье анализируются особенности проявления историко-культурной дуальности староверов в их контактах с советской властью и ее институтами. Делается акцент на сложности и неоднозначности функционирования феномена «свой - чужой» в бытовой философии и языковом сознании этих людей. Говорится о том, что данная оппозищия является смыслообразующим маркером в условиях культурной консервации верующих.

Отмечается сохранность церковнославянской традиции в области книжного

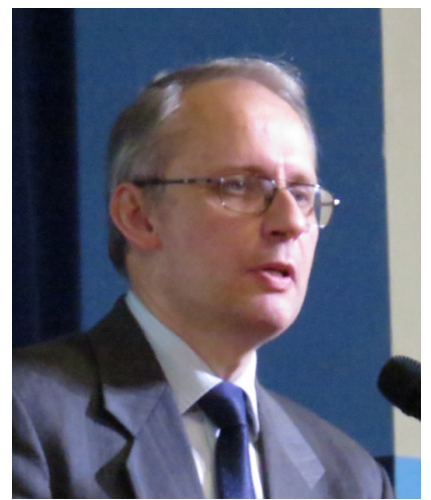
дела. Комментируются сведения об особенностях библиотечных собраний скитников. Уточняются словесные детали в речевом обиходе старообрядцев. Констатируется, что их язык выступает в качестве маркера конфессиональной культуры - своеобразной константы жителей тех мест, отличающей их от мирского населения. Доказывается, что словесный ряд в коммуникации пустынников представляет собой особый социолект, наполненный как традиционной церковнославянской лексикой, так и специфическими оборотами с элементами местного говора.

Оценивается филологическая уникальность представленных текстов в аспекте диалога культур и источниковедческой традиции ХХ в.

Ключевые слова: Тува; полевые записи; старообрядцы Тувы; культурная идентичность; источниковедение; свой - чужой; метакультурная константа; коммуникативное сознание; книжная культура; языковая личность

Для цитирования:

Валентинова О. И., Никитин О. В. Метакультурные константы и связи старообрядцев Тувы (на материале путевых записей археографической экспедиции Н. Н. Покровского 1967 г.) // Новые исследования Тувы. 2021 , № 3. C. 195-209. DOI: https://www.doi.org/10.25178/nit.2021.3.15

Валентинова Ольга Ивановна - доктор филологических наук, профессор кафедры общего и русского языкознания филологического факультета Российского университета дружбы народов. Адрес: Россия, 117198, г. Москва, ул. Миклухо-Маклая, д. 6. Тел.: +7 (499) 936-85-73, доп. 2573. Эл. адрес: ovalentinova@yandex.ru

Никитин Олег Викторович - доктор филологических наук, профессор кафедры русского языка Петрозаводского государственного университета. Адрес: 185910, Россия, г. Петрозаводск, пр-т Ленина, д. 33. Тел.: +7 (8142) 71-10-73. Эл. адрес: olnikitin@yandex.ru

VALENTINOVA, Olga Ivanovna, Doctor of Philology, Professor, Department of General and Russian Linguistics, Philological faculty, RUDN University. Postal address: 6, Miklukho-Maklai St., 117198 Moscow, Russian Federation. Tel: +7 (499) 936-85-73, IT: 2573. Email: ovalentinova@yandex.ru ORCID ID: 0000-0002-8510-8701 NIKITIN, Oleg Viktorovich, Doctor of Philology, Professor, Department of Russian, Petrozavodsk State University. Postal address: 33, Lenin Prospect, 185910 Petrozavodsk, Russian Federation. Tel.: +7 (8142) 71-10-73. Email: olnikitin@yandex.ru

ORCID ID: 0000-0003-2815-6691 
Article

\title{
Metacultural constants and the connections of the Old Believers of Tuva (from the travel records of the 1967 Archeographic expedition led by N. N. Pokrovsky)
}

\author{
Olga I. Valentinova \\ RUDN University, Russian Federation, \\ Oleg V. Nikitin \\ Petrozavodsk State University, Russian Federation
}

\begin{abstract}
The article analyzes the metacultural constants of the Old Believers of the Republic of Tuva as seen in the materials of the archeographic expedition of led by N. N. Pokrovsky (1967). The authors consider field records left by researchers an original monument of written culture of the time. It is also a source of personalized information about the number, composition, education, religious rites and spiritual values, everyday customs and speech and behavioral tactics of the Old Believer population in the region.

The documents under research characterize the relations between the inhabitants of the sketes and "people of the world". The article focuses on the manifestation of the historical and cultural duality of the Old Believers in their contacts with the Soviet government and its institutions. A special accent is made on the complexity and ambiguity of the binary opposition of "own" $v$. "alien" in the everyday philosophy and language consciousness of this group. The binary is seen as a crucially important marker for the conservation of their culture.

The authors also note the survival of the Church Slavonic tradition in the field of bookmaking, with a special comment on the skete library collections. The authors clarify some details in the speech of the Old Believers. It is stated that their language acts as a marker of confessional culture which makes it a permanent feature for the local dwellers which sets them apart from the "people of the world", i.e. secular population. It is proved that the words skete people use in communication are part of a special sociolect, which contains both traditional Church Slavonic vocabulary and specific phrases making use of the local dialect.

Finally, the authors evaluate the philological uniqueness of the presented texts in the aspect of the dialogue between cultures and the source study tradition of the 20th century.
\end{abstract}

Keywords: field records; Old Believers of Tuva; cultural identity; source studies; "own v. alien" opposition; metacultural constant; communication consciousness; book culture; linguistic personality

For citation:
Valentinova O. I. and Nikitin O. V. Metakul'turnye konstanty i sviazi staroobriadtsev Tuvy (na materiale putevykh
zapisei arkheograficheskoi ekspeditsii N. N. Pokrovskogo 1967 g.) [Metacultural constants and the connections of the
Old Believers of Tuva (from the travel records of the 1967 Archeographic expedition led by N. N. Pokrovsky)]. New
Research of Tuva, 2021, no. 3, pp. 195-209. DOI: https://www.doi.org/10.25178/nit.2021.3.15

\section{Введение}

Изучение культуры старообрядчества Восточной Сибири в последние годы вызывает повышенный интерес исследователей из-за уникальности исторических, этнографических, религиозных, ландшафтных и языковых условий данного региона. В этот ареал входит Республика Тыва, многоликая культура, неповторимый бытовой колорит традиционного уклада жизни, веротерпимость, особый менталитет местного населения которой представляют собой очень ценные объекты исследования. Массовое переселение старообрядцев в Туву началось в конце XIX века (Этнография старообрядцев ..., 2014). Процесс освоения новых территорий способствовал расширению историко-культурного ареала староверов Сибири.

В советский период, как справедливо пишут М. П. Татаринцева и А. А. Стороженко, «старообрядчество изучалось с позиций воинствующего атеизма» (Татаринцева, Стороженко, 2015: 7). Постепенно, с конца 1980-х годов, идеологические «оковы» науки начинают слабеть, и предметом внимания становятся хозяйственные отношения, церковно-государственные связи, духовная и книжная культура, проблемы миграции староверов. Появляются исследования конфессиональных меньшинств в 
историческом контексте и современном социуме (Стахеева, 1998; Покровский, Зольникова, 2002; Покровский, 2003; Стороженко, 2004; Татаринцева, 2006; Татаринцева, Моллеров, 2016: 195-205; Люндуп, 2019), публикации и анализ литературного творчества пустынножителей Восточной Сибири, Алтая, Республики Тыва (Покровский, 1984; Духовная литература ..., 1999; Журавель, 2012; Липинская, Леонтьева, 2012; Урало-сибирский патерик ..., 2014-2016).

В русле поликультурной направленности журнала «Новые исследования Тувы» эта проблематика получила активное распространение - спецвыпуск № 12019 г. был посвящен изучению русского мира Тувы и старообрядческим традициям «енисейского меридиана» (Быкова, Пригарин, 2019; Данилко, 2019; Дутчак, 2019; Костров, Моррис, 2019; Рыговский, 2019; Стороженко, 2019; Татаринцева, 2019; а также: Пригарин, Стороженко, Татаринцева, 2020). Мы хотим продолжить изучение закрытой религиозной общности с необычной стороны - путем проникновения в конфессиональное пространство языковых личностей «матушек» и «отцов», в мир их субкультуры глазами советского ученого.

В настоящей статье авторы анализируют тексты археографических экспедиций академика Н. Н. Покровского 1960-х гг. (Дневник археографической ..., 2016).

Особую ценность, на наш взгляд, представляют буквальные записи «с голоса» информантов. В путевых заметках много места отведено догматическим спорам пустынножителей, открывающим ученым философию их духовного облика. Книжность староверов как специфический маркер их бытия также во многом интересна и заслуживает внимания исследователей. Все это позволяет изучать метакультурные константы старообрядцев, характеризовать своеобразные рече-поведенческие тактики и анализировать их традиции. Эти материалы послужили основной источниковедческой базой нашего исследования.

Целью работы является лингвокультурный, социально-исторический анализ жанра полевых записей второй половины XX века как оригинального памятника по изучению древлеправославия и выявление культурных доминант в бытовом, конфессиональном и коммуникативном сознании представителей согласия часовенных, определявших принципы их поведения и общения.

\section{Характеристика полевых заметок}

Дневник археографической экспедиции Н. Н. Покровского - оригинальный культурно-исторический памятник, своеобразная летопись часовенного согласия Тувы. Ученый писал, что идею совершить археографическую экспедицию в Туву ему подал академик М. Н. Тихомиров, но первый поход в места заселения староверов оказался неудачным. Это не остановило исследователей, и вскоре они осуществили новую поездку и нашли в скиту о. Палладия настоящую библиотеку из нескольких десятков томов и «действующий скрипторий, средневековую мастерскую по переписке, ремонту и переплету древних книг» (Покровский, 2003: 16).

Особенностью дневника является факт обработки имевшихся в распоряжении участников экспедиции бумажных записей, так как они не пользовались диктофоном и фиксировали рассказы своих информантов по памяти после беседы с ними (Зольникова, 2016: 271). Н. Н. Покровский отлично владел методикой проведения полевых работ и знал, как нужно проводить экспертное интервью.

Записи участников экспедиции не были хаотичными: отмечались и структурировались самые важные для научного исследования факты жизни и деятельности «пустынников», объединенные в проблемные блоки: «Споры о Софии Премудрости божией», «О порядке крещения», описание скитских поселений, биографии отшельников, рассказы об истории старообрядческих семей и др. (Дневник археографической ..., 2016: 182-185). При описании скита Варсонофии в дневник вносятся сведения о населении с поименным перечислением, указанием возраста, мирского имени, иных сопутствующих деталей: «боля-я-ящие три бабки», «нетрудоспособные» (там же: 185). Здесь же дается подробное описание хозяйства скита: огород и скот, строительные работы, взносы и др. (там же). Отдельно излагается биография Варсонофии и указываются необычные детали: говорится, что она работала в колхозе сторожем, «была послана на ВДНХ в Москву, там осмотрела все храмы и иконы в них, но ничего не знала об иконах в Третьяковке, о чем до сих пор жалеет» (там же: 186). Данные биографии сопровождаются рассказами о бывших и нынешних родственниках, взаимоотношениям с ними.

Фактологическая точность описания, умение получить у неразговорчивого жителя скита необходимую информацию, высокая степень атрибуции деталей, внимание к индивидуальным особенностями носителей старой веры, способность увидеть их непростую жизнь изнутри и отметить 
социальные противоречия в быту и вере насельников, которые мы видим в записях, позволяют утверждать, что Н. Н. Покровский и его соратники действительно сделали прорыв в атеистическом сознании современников, показав реальных староверов без искажения, присущего советской идеологической установке.

То, что сейчас называют методикой интертекста, исследователи 1960-х годов успешно применили в ходе полевой практики: они почти буквально пересказывали беседы со старообрядцами с включением косвенной речи и добавлением элементов «со слов» других свидетелей, маркировали значимые для них фрагменты богословских дискуссий, приводили в качестве доказательств цитаты-примеры и цитаты-аргументы. Перед нами совершенно особый документ, представляющий собой синтез прецедентных текстов, в основании которых определенная ситуация с ее исходным компонентом (датой, значимым событием, именем и т. п.), осмысляемая сквозь призму коммуникативного сознания и исторической памяти верующих. Н. Д. Зольникова назвала такой подход методом «включенного наблюдения» (Зольникова, 2016: 273).

Тогда как А. Ф. Емельянов, возглавлявший лекторскую группу в Тувинском обкоме партии и имевший доступ к закрытым документам, выпустил две книги документальных повестей и рассказов о тувинских староверах «От мира не уйти» и «Староверы» ${ }^{1}$, в которых вел борьбу с религией. Описание их жизни А. Ф. Емельянов намеренно сводил к паразитизму (портрет о. Палладия) и агитации против советской власти, показывая мир скитов как чужой²

Тем важнее опубликованные полевые записи, которые в то время не предполагали публичности и преследовали сугубо научные задачи. «Дневник» группы Н. Н. Покровского дал богатый материал и в историко-культурном отношении: в нем подробно описана конфессиональная корпорация часовенных в судьбах, характерах и лицах ее лучших представителей.

\section{Дуальность «свой - чужой» в поведенческой культуре староверов}

Оппозиция «свой - чужой» в языке и культуре старообрядцев проявляется на разных уровнях. Часовенные как закрытая конфессиональная группа обладают характерными признаками социальной и духовной идентичности, которые свойственны в широком понимании и другим этнологическим общностям (ср. противопоставление: норма - антинорма). Но в среде староверов категория сакральности имеет значительно больший, часто доминантный характер и определяет рече-поведенческие тактики представителей исследуемой субкультуры. Ср. характерные для них оппозиции: добро от Бога - зло от дьявола; наша вера - чужая вера. В записях экспедиции зафиксировано, что отец одной насельницы не разрешил ей вступить в канонический брак «за человека иной веры пока тот не перейдет в их веру» (Дневник археографической ..., 2016: 161; здесь и далее во всех цитатах выделение полужирным шрифтом наше. - О. В., О. Н.). С. Е. Никитина верно подметила данную особенность в языке русского религиозного фольклора староверов, когда писала, что эта дуальность есть смысловое отражение доминантных понятий в системе ценностей старообрядцев: «Борьба этих начал происходит в социальных сферах, а также в человеческой душе...» (Никитина, 2017: 79).

Интересны факты взаимодействия староверов с учителями и отношение первых к обучению детей. Здесь возникает нравственная дилемма: светские представления о людях иной веры накладываются на принятые в то время стереотипы «о саботаже», идущие, очевидно, от официальной пропаганды, десятилетиями создававшей свой облик староверов как непокорных, «чужих». Говоря о Зинаиде Филипповне, Н. Н. Покровский и его коллеги отметили такую особенность ее поведенческой культуры: она возмущалась тем, что учителя «плохо делают свое дело, ибо перекладывают свои задачи на родителей (заставляют писать с детьми диктанты, решать зад[ачи] по алгебре)» (Дневник археографической ... , 2016: 155). Официальная позиция директора звучала сурово: он посчитал, что старообрядцы не желают учить своих детей «по религиозным соображениям, и угрожал принятием административных мер против родителей» (там же). Однако Зинаида Филипповна «оправдывалась» и хотела, чтобы ее дети учились хорошо. Она советовалась с педагогами о методах воспитания, «как их наказывать и когда», и полагала, что «даже в тайге образованному лучше» (там же).

${ }^{1}$ См.: Емельянов А. Ф. От мира не уйти: Документальные повести и очерки. Кызыл : Тувинское книжное изд-во, 1984. 240 с.; Емельянов А. Ф. Староверы: Повесть. Кызыл: Тувинское книжное изд-во, 1991. 125 с.

${ }^{2}$ Емельянов А. Ф. От мира не уйти: Документальные повести и очерки. Кызыл : Тувинское книжное изд-во. 1984. C. 26, 72-78. 
Оппозиция «свой - чужой» выражается и в отношении староверов к советским традициям: служба в армии, вступление в комсомол и др. В первом случае они готовы пойти на компромисс и свое поведение объясняют «строгими правилами». Если идешь «с Богом в душе», рассуждают они, тогда можно. Вот как пересказали их убеждения участники экспедиции Н. Н. Покровского: «При царе старообрядцы ходили воевать, поскольку там помнили Бога, а при советск[ой] власти, которая борется с Богом, они стараются уклониться любыми средствами» (там же). И еще один важный тезис характеризует духовную установку пустынножителей: «Служить должны все, но нельзя отрекаться от Бога» (там же: 158). Авторы полевых заметок, комментируя этот сюжет, пишут о том, что староверы все же делают уступки времени, сохраняя Божий страх, с которым можно идти и в бой, потому что такой человек «спасется» (там же).

Участники экспедиции отмечали интерес староверов к необычным посетителям. Иногда в разговорах речь заходила и о достижениях научно-технического прогресса. Так, о. Палладий с интересом слушал рассказ ученых об испытаниях атомной бомбы, «но при этом молчал» и не предпринимал «пропагандистских» попыток устрашения приближающимся концом света (там же: 182). Эта характеристика поведенческой культуры - молчание - тоже является типичной приметой дуальности «свой - чужой».

Вообще каждое согласие имело свои частные правила и отношения внутри социума и за его пределами. По наблюдениям М. П. Татаринцевой и Н. М. Моллерова, жесткость градации на «своих» (монашествующих) и «чужих» (мирских) в толке часовенных «и сегодня обгоняет большинство других направлений старообрядчества, за исключением разве бегунов-странников» (Татаринцева, Моллеров, 2016: 199).

Записи участников экспедиции зафиксировали, что сношения со светскими людьми у староверов сохраняются: у некоторых дети имеют гражданские профессии и живут отдельно. Но и здесь оппозиция «свой - чужой» четко проявляется в поведенческой культуре. Например, матушка Акилина вела переписку со своим сыном, работавшим в паспортном столе начальником. Он упрашивал ее возвратиться к мирской жизни, «причем заявился в скит в милицейской форме» (Дневник археографической ... , 2016: 188). По словам монахини, она не решила, что ему ответить. И далее авторы полевых записей делают такое примечание: «т. е. положительный ответ не исключен» (там же).

Итак, оппозиция «свой - чужой» присутствует во многих рассуждениях староверов и является непременным свойством их религиозно-бытовой культуры. Наиболее частотны дуальные пары: добродетельное - греховное, церковное (каноническое) - мирское (гражданское), традиционное (обучение, воспитание) - советское, с Богом в душе - без Бога в душе, своя посуда - чужая. Примеров такого противостояния духа, отмеченного участниками экспедиции, немало, ср.: Филипп Васильевич Долгов был призван в действующую армию (имеется в виду Первая мировая война) и находился в Германии, «но не обмирщился, ел отдельно и соблюдал устав о молитвах и посте» (там же: 161). Указанный дуализм, как отмечают исследователи старообрядчества (Иванова, 2014; Никитина, 2017; Покровский, Зольникова, 2002), проявляется не только в реальной коммуникации, но и в литературных произведениях и отражает ценностные представления скитожителей о «ветхозаветной» модели мира и их духовные константы.

\section{Споры о вере в коммуникативном сознании часовенного согласия}

Прошлое в сознании староверов сближается с настоящим так плотно, что события трехвековой давности становятся фактом их личной жизни. Авторы полевых записей непроизвольно вовлекаются в мироощущение своих собеседников. Жительница Ужепа Зинаида Филипповна Микова рассказала о чине венчания, который совершали старики, так называемые венчальники. Участники экспедиции запишут: «Помнит (знает), что до Никона венчали в церкви» (Дневник археографической ..., 2016: 154). Дальнейшая правка - зачеркнули «помнит» и скобки, в которых было слово «знает», - меняет концептуально значимую точку зрения героини рассказа (помнит) на отстраненно нейтральную знает.

Реформа Никона, рассекающая жизнь каждого древлеправославного на до и после с самого их отделения от церкви и отлучения на соборе 1667 г., непрерывно и напряженно обдумывается, продолжая все более и более разделять ищущих чистоты ревнителей веры. Дневник экспедиции дважды запечатлевает неостанавливающийся раскол: о выделении в конце XVIII - начале XIX века из беглопоповщины часовенного согласия расскажет о. Палладий, а о выделении за несколько лет до 1967 года из часовенного согласия михайловской группы расскажет Зинаида Филипповна Микова. 
Древлеправославные, не имея своего епископа, но полагая, что он может быть где-то далеко, сначала брали к себе священников дониконовского поставления, а когда их не осталось, решили принимать священников-никонианцев, но крещенных по дониконовскому чину. Когда же и их не стало, вынуждены были приглашать беглых священников, которые часто скрывались от суда за преступления. Поэтому беглопоповцы старались внимательно отбирать беглых попов. Но со временем, на рубеже XVIII-XIX веков, беглопоповцы начинают принимать к себе «много сомнительных попов» (там же: 180). Противники этого, рассказывает о. Палладий, выделяются в согласие, которое назовут часовенным. Из всех возможных пороков беглых попов после беседы с о. Палладием ученые занесут в дневник только один - крещение обливанием, а не погружением. Выразили ли так исследователи старообрядчества крайне высокую степень этической щепетильности сторонников часовенного согласия, или хотели подчеркнуть особенное внимание именно к нарушению обряда, или просто записали то, что им показалось интересным, по контексту этих записей определить невозможно. Но одно совершенно достоверно: о. Палладий говорил о крещении обливанием как о пороке, не дающем соблюсти истинную веру. Со слов о. Палладия, последнего «правильного» священника приняли в 1839 г. (там же: 180). Поэтому в не имеющем священников часовенном согласии четыре таинства (причастие, покаяние, крещение и венчание) из семи - совершаются не полностью: из обряда суточного круга богослужений исключали те его части, которые мог произносить только священник. А таинства миропомазания, первоначально совершавшееся только епископом, а потом на Востоке пресвитерами (священниками), елеосвящения, которое осуществлялось собором семи «служителей алтаря», и архиерейского священства не совершают.

Часовенные были вынуждены отказаться и от литургии. А причащение совершалось раз в три года святыми дарами, сохранившимися со времени «правильного» священства и с дониконовской эпохи.

На пустом обороте тетради двумя участниками экспедиции были сделаны примечания, раскрывающие другую особенность восприятия древлеправославными дониконовской эпохи и губительной реформы - сохранилась связь не с абстракцией, а с событиями и людьми того времени. Так, матушка Измарагда говорила (по записям О. К. Крокинской), что ее причастие дониконовское «от какого-то инока, кажется, Филиппа и что от него же все время разбавляется богоявленская вода. Он, Филипп, был священник и святил воду, погружая в нее крест» (Дневник археографической ..., 2016: 180-181). О том, что Филипп выжил после подавления восстания, запишет Г. П. Енин (там же).

Первоначальная неопределенность - «от какого-то инока, кажется, Филиппа» - вымещается точностью фактов: кем был Филипп и где, как святил воду. Его судьба связана с Соловецким монастырем, восставшим после реформы Никона и восемь лет, с 1668 по 1676 г., сопротивлявшимся нововведениям.

Стремление к совершенной подлинности выделило в начале шестидесятых годов прошлого века уже из часовенного согласия еще одну группу староверов (михайловские), которые учат, что таинство причастия после реформы Никона исчезло полностью вместе с истинным священством (там же: 160).

Но не все разногласия приводят к дальнейшему разделению. Характерные для староверов споры о пришествии антихриста - придет он только духовно или и духовно, и чувственно - не нарушают единства часовенного согласия.

Самой непримиримой позиции придерживались пришедшие в Ужеп с запада «духовники», то есть те, кто верил только в духовное пришествие антихриста и считал, что оно уже состоялось: одна старуха «резко обличала Палладия», со слов З. Ф. Миковой (там же: 159).

Отец Палладий прямо своего мнения не высказал: «уклонился от откровенного разговора» и только «сделал туманный намек» (там же: 182), что, кто не признает причастие, тот верит только в духовное пришествие.

Размышления о вере и вызванные ими разногласия и споры и для шестидесятых годов XX века являлись константой повседневного сознания староверов. Они свидетельствовали о сосредоточенной умственной и душевной жизни. Знаменитый историк Н. И. Костомаров, изучавший этот конфессиональный разрыв в русской православной традиции, признал раскол «крупным явлением народного умственного прогресса» (Костомаров, 1994: 265). Он писал, что трагическое событие побудило народ «не в отдельных личностях, а в целых массах», без влияния власти и образованного духовенства к своеобразной деятельности «в области мысли и убеждения» (там же).

Спор об антихристе не привел к разделению. Староверы продолжали вместе молиться и совершать трапезу. Об этом единении говорили и Зинаида Филипповна (Дневник археографической ... , 2016: 160), и Капитолина Филипповна (там же: 164). 
В описании богословских споров внутри общины особенно остро ощущается информационная недостаточность дневниковых заметок, особенно в части, когда речь шла о духовном и физическом пришествии антихриста: «Мы не могли постичь хода споров ..., какое же из этих двух явлений будет раньше» (там же: 182).

Что побудило ученых отказаться от фиксации этих споров, от дословного или близкого к нему воспроизведения намеков о. Палладия и его уклончивости в разговоре, утверждать однозначно сложно. Но похоже, что на этот раз запечатлеть диалектику богословской мысли староверов помешал отчасти атеистический скептицизм, заметный в текстах путевых записей. Однако ясно, что Н. Н. Покровский и его группа увидели в простых информантах ту неуспокоенность, любовь к философствованию и «мыслетворчеству», которые были отличительной особенностью староверов, не признававших авторитетов официальной духовной и светской власти, выражавших словесно свои протесты. Н. И. Костомаров тонко подметил эту черту в коммуникативном сознании поборников старой веры: «Какие бы признаки заблуждения ни представлялись в расколе, все-таки он соединялся с побуждениями вырваться из мрака, умственной неподвижности, со стремлением русского народа к самообразованию» (Костомаров, 1994: 292).

\section{Чтение и книжность в конфессиональной культуре часовенных}

Чтение - естественная часть повседневной жизни староверов. Описание книг, как и рассказы о хозяйстве, - обязательная составляющая путевых записей. В дневнике нет полного перечня книг (потому, что исследователям не давали доступа к этим священным собраниям), участники экспедиции только вспоминают, иногда с небольшим комментарием, те издания, которые видели. Описание книг строгого в вере Филиппа Васильевича Долгова - отца Зинаиды Филипповны Миковой и Капитолины Филипповны Долговой - так и начинается: «Мы видели у него следующие книги...» (Дневник археографической ..., 2016: 161). С точки зрения археографии у Филиппа Васильевича Долгова очень интересные книги: рукописный Октоих; вышедший в Москве печатный Требник 1638 года, достоверность которого подтверждена водяным знаком; следованная Псалтирь, изданная в Почаеве в 1781 г.; Устав малый 1910-х годов.

Октоих, написанный самим Филиппом Васильевичем около 30 лет назад, отметят авторы «Дневника ...», крюковый (там же: 161). Эта лаконичная помета отсылает к знаменному пению, записываемому знаменами, то есть знаками, - древнейшему церковному одноголосному пению, сохранившемуся только у староверов. Н. Ф. Соловьев отмечал, что оно среди других типов распевов занимало «первое место по художественности и богатству мелодического и ритмического содержания» (Соловьев, 1993: 561). Запись нотными знаками ранневизантийского происхождения (крюками) отличала сосредоточенность на смысле текста.

Необходимейшая в богослужении и жизни Псалтирь, переведенная еще Кириллом и Мефодием, изданная в Почаеве, в Почаевском монастыре, - последованная. Так называется книга псалмов в соединении с Часословом - сборником псалмов и молитв к определенному времени богослужения.

Устав малый - книга старообрядческая. В ней объединены предписания Типикона о порядке и образе совершения церковных служб и местные уставы дониконовских монастырей.

Как и у отца, книги Капитолины Филипповны Миковой - религиозного содержания. Среди них печатный и рукописный Азбуковник XIX века с дониконовского издания типографии Бурцева. До Азбуковника 1634 года грамоте учились по Псалтири.

Авторы «Дневника ...» отметили, что у Капитолины Филипповны были и православные Четьи Минеи. Скорее всего речь идет о Четьи Минеи святого Димитрия Ростовского, которые издавались много раз. Вероятнее всего, именно эту многотомную книгу Капитолина Тихоновна «пыталась подобрать всю. Она очень интересовалась, чем православные Четьи Минеи отличаются от старообрядческих» (Дневник археографической ..., 2016: 163).

Есть у Капитолины Филипповны и чужие книги: Псалтирь печатная и Кормчая Фалелея (древнейший в Русской православной церкви сборник юридических текстов, восходящий к византийскому праву). А. П. Обновленский дает известное символическое понимание Кормчей: «Если церковь сравнивают с кораблем, пребывающие на котором не гибнут в житейском море, то как кораблю нужен кормчий, который направлял бы его путь, так и церкви, пребывающей в мире, нужно водительство» (Обновленский, 1993: 828). 
Книги в скиту Варсанофии описываются очень обобщенно в путевых записях экспедиции: дониконовское рукописное Евангелие тетр, четвероевангелие, середины XVI века; дониконовский старопечатный Апостол 1-ой половины XVII века, конец которого рукописный XVI века; елизаветинское, XVIII века, издание Библии с вырванным портретом императрицы и надписью рядом «раскольница» (Дневник археографической ..., 2016: 189).

В скиту матушки Евгении ученые отмечают только том невежинского, известного мастера Московского печатного двора Андроника Невежи, Октоиха 1594 года, переплетенный Палладием (другой том - у о. Палладия).

Из книг же о. Палладия в путевых записях отмечают (кроме упомянутого выше тома невежинского Октоиха) только уникальный сборник, написанный его рукой, в котором были «родословие» согласия, постановления соборов и выписки из исторических сочинений о староверах (там же: 179). Богатейшую библиотеку и мастерскую о. Палладия, так поразившие экспедицию, Н. Н. Покровский восторженно опишет в своем «Путешествии за редкими книгами» (Покровский, 1984: 21).

За эти одиннадцать дней участники экспедиции видели советские газеты и журналы только в семье Миковых, живущей в Ужепе. Разнообразие выписываемых ими изданий отражает интерес, даже если он и вынужденный, к официальной общественной жизни («Тувинская правда»), увлечение семьи охотой, пчеловодством и, очевидно, ожидание призыва в армию («Советский воин») старшего сына (Дневник археографической ..., 2016: 158).

Круг чтения Миковых отражает непроизвольный дуализм сознания староверов, вызванный изменением окружающей жизни. Из взрослого поколения Миковых, Долговых, Рукавицыных все получили домашнее церковное образование, и только Фалелей Терентьевич и Зинаида Филипповна Миковы имеют еще и гражданское образование. И все же умение читать по-церковнославянски «было для старообрядца очень важно» (Татаринцева, 2006: 105).

Итак, судя по записям экспедиции Н. Н. Покровского, круг чтения древлеправославных был весьма широким и не ограничивался только богословскими сочинениями. Но они составляли особенную гордость владельцев, показывали преемственность духовной традиции от дониконианцев. Осмысленное чтение таких текстов и применение полученных знаний на практике (необязательно в церковной жизни) составляло одно из самых важных компонентов образования староверов. М. П. Татаринцева и Н. М. Моллеров очень точно высветили эту константу их конфессиональной культуры, полагая, что установки, сюжеты и образы, представленные в церковных сочинениях, были во многом для пустынножителей руководством к применению в своих повседневных делах (Татаринцева, Моллеров, 2016: 199). Н. Н. Покровский в свое время это явление назвал страстной актуализацией «авторитетных текстов» (Покровский, 1984: 146; Татаринцева, Стороженко, 2015: 20).

Известные исследователи старопечатных сочинений Сибири Е. И. Дергачева-Скоп и В. Н. Алексеев подметили и другую особенность влияния книжности староверов на их поведенческий быт: культура, основанная прежде всего на книжном опыте (а не на школьном воспитании), «порождает обычно многочисленные варианты самовыражения человеческого духа. В ней с особой силой проявляется то, что называется “самовластием души”» (Дергачева-Скоп, Алексеев, 2003: 28). Причем староверы, привязанные традицией к книге как к духовному «окормлению», понимают, что этот источник «Божьей правды» «надежно обеспечивает их “самовластию души” “заграду верой”» и укрепляет их силу «духовного единения» (там же). По сути, церковная книжность как маркер конфессиональной культуры скитников скрепляла их нравственно, подпитывала исторически и удерживала веру от посягательств мирской жизни в период борьбы с «изжитым прошлым».

\section{Язык как метакультурная константа духовного облика старообрядцев}

Из филологов начала XX века первую авторитетную монографию о говорах и социокультуре ревнителей древнерусской традиции Восточной Сибири написал знаменитый славист А. М. Селищев, наблюдавший так называемых «семейских» (Селищев, 1920). В настоящее время интересные наблюдения о современном конфессиональном письме староверов и их лексиконе были представлены в публикации А. А. Пригарина, А. А. Стороженко, М. П. Татаринцевой (Пригарин, Стороженко, Татаринцева, 2020).

Между тем проблемы культуры понимания старообрядческого слова и отношение древлеправославных к филологической экзегетике в целом представляют собой весьма интересный и малоизученный аспект духовной литературно-книжной практики пустынножителей (Бахтина, 1999; Бураева, 2018; Журавель, 2012). 
В плане экспедиции группы Н. Н. Покровского этот вопрос не стоял. Но все-таки им удалось подметить интересные черты речевой практики староверов, записанные с их же слов. Ученые, например, хотели выяснить разницу между названиями толков староверов. В одной из первых бесед с Зинаидой Филипповной возник такой ономастический сюжет: свое согласие она именует «христианами», прибавляя, что «остальные названия даны другими» (Дневник археографической ... , 2016: 159). Капитолина Ф. объясняла, что «“чашечники” - издевательское название», а иные «титулы» «не очень точные» (там же: 159). Она разъясняла эту словесную «загадку» так: «“Часовенное” - правильно, но дело не только в часовнях. У отца Палладия, действительно, часовня (рядом с келарней), но вообще-де часовен мало» (там же). В беседе с ней зафиксировано еще одно именование староверов «стариковщина», о котором информант ничего не слышал (там же). Показательно, что староверка отличает «обидное» наименование от канонического и остро реагирует на неверное, с ее точки зрения, слово. Эта рече-поведенческая тактика - отстаивать «Божье дело», не искажать картину вероучения заметна и в других беседах староверов. Каждое их слово наполнено смыслом, и не допускается, когда вопрос касается истинной веры, двоичного, искаженного толкования или «издевательского» подтекста.

Н. Н. Покровский и Н. Д. Зольникова приводят замечательный рассказ, свидетельствующий о борьбе «священным словом» с техническими новшествами безбожников, воспринимавшимися староверами как «бесовские чудеса». Он представлен во второй книге Патерика, где повествовалось о том, как с помощью самых действенных методов - крестного знамения и молитвы - можно заставить замолчать радио. Матушка Акинфа силой духовного слова это сделала в клубе концлагеря, а матушка Евстолия, будучи мирской, в своем доме, где «по воле любившего развлечения мужа, “было радио, которое незатыкаемо бе все гласило” (Покровский, Зольникова, 2016: 263).

Участники экспедиции 1967 г. отметили специфическую богословскую лексику староверов и целый понятийный ряд, отражающие особенности их религиозных устоев.

Накрытый (накрытая) - тот, кого посвятили в «черноризцы» - надели монашеское одеяние (Дневник археографической ..., 2016: 210), но еще не постригли в монахи (см. ниже). Например, так говорится о Филимоне Соколове, который в молодые годы «был накрытый, потом ушел в мир» (там же: 158). Указанное слово в рассказах староверов, по данным «Дневника» экспедиции, встречается довольно часто.

Этот церковный обряд вызвал интерес у группы Н. Н. Покровского. Капитолина Федоровна так объяснила им суть обряда: перед «накрытием» должен быть испытательный срок у старца в скиту, от которого полностью зависит кандидат. Самое важное в ритуале «накрытия» - четкое соблюдение положенного в конфессиональном социуме «чина» (в данном случае имеется в виду то, что скитские одежды, мантия и камилавка, «возлагаются» на кандидата, и это решает его дальнейший статус в иерархии скитожителей). Полевые записи разъясняют далее священный смысл этого действия чудесным значением обряда: «...даже случайно накинувший на себя мантию или прикоснувшийся к ненадетой мантии обязан стать монахом...» (там же: 165).

Принять чин - быть насельником-черноризцем скита. В путевых заметках экспедиции говорилось о Филимоне, который вернулся домой беглецом-дезертиром «и заявил, что хочет покаяться, вернуться в скит и “принять чин” (не накрыться)» (там же: 158).

В часовенном согласии, как рассказал о. Палладий участникам группы Н. Н. Покровского, было три типа «пустынников»: первый составляли иноки, которые приняли постриг, ко второму относили накрытых черноризцев, «надевших чин, но не постриженных» (там же: 173-174), а к третьим - всех остальных насельников.

Слово чин имеет несколько обозначений в языке староверов, но чаще всего его смысл сводится к двум понятиям:

1) чин как одежда при накрытии послушника / послушницы, обычно готовится (вышивается) из «старинных материалов», какие были в распоряжении скитников. О них упомянула матушка Надежда в беседе с участниками экспедиции Н. Н. Покровского. Она говорила, «что весь ее чин сшит из старого сарафана ее бабушки» (там же: 170);

2) чин, то есть определенный порядок ритуального действия: «В их согласии (часовенное) есть порядок (чин) для венчания...» (там же: 165).

В последнем случае «брачующиеся произносят форму согласия, получают наставления» (там же). Значит, этот обряд сопровождался и словесным ритуалом (к сожалению, авторы текста его не дают). 
Приведем и другие яркие примеры словотворчества староверов:

потопить божество - означало уничтожить предметы религиозного быта (иконы) и книги - из рассказа Зинаиды Филипповны о том, как в период Гражданской войны монголы напали на таежную заимку староверов, избили их и «потопили все божество» (там же: 154);

богородичный [кусочек хлеба] - использовался в качестве элемента причастия и мог храниться «врезанным в икону Богородицы» (там же: 160);

гостиница - отдельное помещение, землянка в скиту о. Палладия для приезжих, но может использоваться для жизни престарелых насельников и больных монахов: «...замыкая первый двор, находится полуземлянка - “гостиница”...» (там же: 168);

жить семьями - несколько насельниц проживают совместно в келье и отдельно от других «семей» ведут хозяйство. Примечательно, что одна «семья» может иметь корову и лошадь (то есть, очевидно, быть более состоятельной по меркам староверов), вторая довольствовалась только коровой, о третьей скитники ничего не могли сказать участникам экспедиции, а у четвертой «есть только куры» (там же: 190);

чи(а)кают [иконы] - издают звук, трещат, щелкают (употребляется в отношении сакральных предметов культа): «...чикают на несчастье, на гостей... икона... “чикала” на наш приход в скит...» (там же: 173).

Это же явление отмечено в «Истории о Дупческом ските» А. Г. Мурачева, который описал то, как «пустынники» понимали «язык извещений» (Духовная литература ..., 1999: 273). Накануне разгрома скитов в 1951 году «иконы стали почикивать, пощелкивать» (там же). В «Истории...» используется для засвидетельствования какого-то особого (чаще всего неприятного) случая схожее выражение иконы извещают.

В текстах путевых заметок появляется и обиходно-разговорная лексика и фразеология, причем ученые-полевики, записывавшие такие слова и выражения, намеренно их заключали в кавычки, выделяли из общего контекста, понимая, что они контрастируют с повествовательным рядом научного дневника. Этим приемом они выделяли личность рассказчика, вводившего в свою речь элементы народной языковой культуры. Так, например, в «Дневнике» есть выражение под ножом: «...в это время отец Палладий был “под ножом” связан Филимоном...» (Дневник археографической ... , 2016: 158-159). В другом фрагменте нам встретилось сочетание бежать на прилавок, которое авторы текста объяснили так: «При появлении всякого нового человека в деревне она бежала на “прилавок” (сбросовая терраса у Енисея)...» (там же: 163).

Внутренние конфликты часовенных, их отношение к богоборческой власти закрепились в выражении уйти в большевики (там же: 191), то есть перейти на сторону советской власти (имеет отрицательную коннотацию).

К диалектным элементам речи староверов можно отнести лексемы домовина (деревянный гроб): говорится о том, что один «древний дед» приехал умирать в скит и приготовил себе «домовину, выдолбив ее из целого кедра» (там же: 167); отмечаются и другие местные словечки типа карпета («торпеда») - способ ловли рыбы, шишковать - собирать кедровые орехи (там же: 168), завинять (там же: 181) - обвинять.

Любопытны реплики, закрепленные в «Дневнике» группой Н. Н. Покровского с уст скитожителей. Так, матушка Надежда «говорила, что Варсанофия и Мастрадея “одного с ними стада”, т. к. еще при отце Игнатии они жили вместе» (там же: 175).

Ученые зафиксировали еще один необычный коммуникативный элемент в речевом обиходе пустынников - наличие прозвищ. Так, матушка Акилина за исключительно активную роль в хозяйстве скита получила клички «“мужик” и “казак”, которыми ее наградили сами староверы» (там же: 188).

Мы опустили здесь наименования церковной утвари, одежды и другие регулярные приметы конфессиональной культуры, так как они почти не отличаются от известных нам названий предметов религиозного культа в традиционном православии. Для нас было важно подчеркнуть своеобычность описания Н. Н. Покровским и его группой речевого обихода пустынников Тувы, язык которых, будь он представлен в путевых заметках более рельефно, несомненно, стал бы предметом более детального анализа специалистов. Но и по указанным нами элементам живого говора, украсившего документальное повествование, можно в дальнейшем проследить интересные особенности бытования речевой культуры жителей скитов в замкнутом пространстве конфессионального сообщества. Это их 
«духовный социолект» с вкраплениями местных слов и выражений обиходного репертуара, наличие религиозной лексики и терминологии, контраст высокого книжного стиля с разговорным, влияние древних книг и рассказанных в них сюжетов на коммуникативную и поведенческую культуру и др. Безусловно, языковые личности староверов - ценный источник по истории формирования их социолектов.

\section{Заключение}

«Дневник археографической группы Н. Н. Покровского» 1967 г. запечатлел типичные и новые черты быта, религиозного обихода, словесности, философии и социально-иерархических отношений в среде представителей часовенного согласия. Их метакультурные контакты проявились в разных аспектах деятельности: во взаимоотношениях внутри и вне своей веры, где четкие религиозные каноны определяли их поведенческую тактику, а частые стычки с властью, пытавшейся изменить их уклад жизни и вписать в новые условия, вызывали отторжение и уход в дальние скиты. На уровне богословских споров также происходила метакультурная полемика между старообрядцами разных согласий и течений. Богатая книжная традиция, сохранившаяся в их обиходе, свидетельствует о высокой образованности людей, оберегавших наследие дониконовской Руси.

Метакультурные связи с местным населением лишь пунктиром проходят по отдельным страницам «Дневника». В хозяйственно-бытовом отношении такие контакты, однако, периодически происходили: купля-продажа земли, материалов для строительства домов, орудий труда и т. д. Правда, староверы, как считает Ч. К. Ламажаа, «не стремились к активному общению ни с тувинцами, ни даже с представителями российского государства» (Ламажаa, 2018: 121). Живя обособленно от тувинцев, в социальном смысле староверы представляли собой монокультуру со своими духовными и поведенческими константами и предпочитали сохранять приемлемые отношения с народом Урянхайского края, даже «владели тувинской разговорной речью».

Полевые записи группы Н. Н. Покровского документально зафиксировали уникальные факты, свидетельствующие о борьбе старообрядцев за сохранение своей идентичности в эпоху атеизма и политических игр властей. Стоит согласиться с мнением М. П. Татаринцевой и Н. М. Моллерова о том, что «в процессе многовековой борьбы с государственным насилием сформировался особый тип личности старообрядиа (курсив наш. - O. В., О. Н.). Стойкость убеждений, твердость в вере, сознание своей правоты во все времена делали старообрядца для государства “неассимилированным элементом”...» (Татаринцева, Моллеров, 2016: 202). Фактически находясь в условиях жесткой консервации, они не потеряли религиозных основ и «памятей» и сберегли традиционный образ жизни, веру предков.

В заключение отметим, что текст «Дневника» интересен как историко-культурный памятник древлеправославия нашего времени, в котором нашли отражение в том числе и языковые особенности местного старожильческого говора. Эти вкрапления невелики (ведь цель экспедиции была совсем иной - археографической), но они подтверждают факт особости микроязыка староверов - наличие еще одной константы, характеризующей их духовный облик. Филологическая ценность «Дневника» несомненна как источника по культуре научного текста, как образца записей речи информантов в сложных полевых условиях и интерпретации полученных от них сведений. Еще и поэтому ученые XXI века так высоко оценивают результаты экспедиции под руководством Н. Н. Покровского, сделавшего новые открытия в глубине Тувы.

\section{СПИСОК ЛИТЕРАТУРЫ}

Бахтина, О. Н. (1999) Старообрядческая литература и традиции христианского понимания слова. Томск : Издво Томского университета. $261 \mathrm{c.}$

Бураева, С. В. (2018) Старообрядческая книжная традиция Енисея: возможности и проблемы компаративного анализа // Вестник Восточно-Сибирского государственного института культуры. № 4 (8). С. 29-38. DOI: https:// doi.org/10.31443/2541-8874-2018-4-8-29-38

Быкова, Е. В., Пригарин, А. А. (2019) Мир визуальных образов старообрядцев Тувы: от иконы и лубочной картинки до фотографии // Новые исследования Тувы. № 1. С. 75-94. DOI: https://doi.org/10.25178/nit.2019.1.6

${ }^{1}$ Емельянов А. Ф. Староверы: Повесть. Кызыл: Тувинское книжное изд-во, 1991. С. 88. 
Данилко, Е. С. (2019) «Смерть ближе рубашки»: похоронная обрядность старообрядцев-часовенных // Новые исследования Тувы. № 1. С. 44-59. DOI: https://doi.org/10.25178/nit.2019.1.4

Дергачева-Скоп, Е. И., Алексеев, В. Н. (2003) Археографические исследования Сибири второй половины 60 начала 70-х годов и формирование коллекции рукописных и старопечатных книг // Книга и литература в культурном контексте: сборник научных статей / сост. и отв. ред.: Е. И. Дергачева-Скоп, В. Н. Алексеев. Новосибирск : РИО ГПНТБ СО РАН. 667 с. С. 23-36.

Дневник археографической группы Н. Н. Покровского 1967 г. (2016) // Урало-сибирский патерик: тексты и комментарии : в 3-х т. / отв. ред. Н. Н. Покровский. М. : Издательский Дом ЯСК. Кн. 2 (Т. 3). 295 с. С. 153-193, $210-212$.

Дутчак, Е. Е. (2019) Сибирские старообрядческие скиты и их паства на рубеже 1920-1930-х гг. // Новые исследования Тувы. № 1. С. 29-43. DOI: https://doi.org/10.25178/nit.2019.1.3

Духовная литература староверов востока России XVIII-XX вв. (1999) : в 3-Х т. / под ред. Н. Н. Покровского. Новосибирск : Сибирский хронограф. Т. 1.800 с.

Журавель, О. Д. (2012) Литературное творчество старообрядцев XVIII - начала XXI в.: темы, проблемы, поэтика. Новосибирск : Издательство СО РАН. 442 с.

Зольникова, Н. Д. (2016) Дневник тувинской археографической группы 1967 г. как источник по истории староверия //Урало-сибирский патерик: тексты и комментарии : в 3-х т. / отв. ред. Н. Н. Покровский. М. : Издательский Дом ЯСК. Кн. 2 (Т. 3). 295 с. С. $270-277$.

Иванова, Н. В. (2014) Лексические репрезентации оппозиции «свой - чужой» в духовных старообрядческих стихах // Научный диалог. № 12 (36): Филология. С. 24-36.

Костомаров, Н. И. (1994) История раскола у раскольников // Костомаров Н. И. Раскол. Исторические монографии и исследования. М. : Чарли. 604 с. С. 265-327.

Костров, А. В., Моррис, Т. Б. (2019) Визуально-текстовая агиография в настенных листах современных старообрядцев часовенного согласия // Новые исследования Тувы. № 1. C. 95-107. DOI: https://doi.org/10.25178/ nit.2019.1.7

Ламажаа, Ч. К. (2018) Национальный характер тувинцев. М. ; СПб. : Нестор-История. 240 с.

Липинская, В. А., Леонтьева Г. А. (2012) Действующий травник с лечебником: Памятник старообрядческой письменности и народной культуры сибиряков. М. : Ин-т этнологии и антропологии РАН. 315 с.

Люндуп, Т. В. (2019) Деятельность научных экспедиций в Туве во второй половине XIX - начале XXI вв.: автореферат дисс.... к. ист. н. Кызыл. 21 с.

Никитина, С. Е. (2017) «Свое - чужое» в языке и культуре русских конфессиональных групп // Вопросы психолингвистики. № 3 (33). С. 76-91.

Обновленский, А. П. (1993) Кормчая книга // Христианство: Энциклопедический словарь : в 3-х тт. М. : Большая Российская энциклопедия. Т. 1.863 с. С. 828.

Покровский, Н. Н. (1984) Путешествие за редкими книгами. М. : Книга. 192 с.

Покровский, Н. Н., Зольникова, Н. Д. (2002) Староверы-часовенные на востоке России в XVIII-XX вв.: Проблемы творчества и общественного сознания. М. : Памятники исторической мысли. 471 с.

Покровский, Н. Н. (2003) Из истории первых новосибирских археографических экспедиций // Книга и литература в культурном контексте: сборник научных статей / сост. и отв. ред.: Е. И. Дергачева-Скоп, В. Н. Алексеев. Новосибирск : РИО ГПНТБ СО РАН. 667 с. С. 15-22.

Покровский, Н. Н., Зольникова, Н. Д. (2016) «Чюдесные события» третьего тома Патерика // Урало-сибирский патерик: тексты и комментарии : в 3-х т. / отв. ред. Н. Н. Покровский. М. : Издательский Дом ЯСК. Кн. 2 (Т. 3). 295 с. C. 213-269.

Пригарин, А. А., Стороженко, А. А., Татаринцева, М. П. (2020) Актуальное конфессиональное письмо: между историографией и биографией (предварительные замечания к рукописи «Заповедная вера. Книга жития и страданий сымских старообрядцев») // Новые исследования Тувы. № 4. C. 180-200. DOI: https://doi.org/10.25178/ nit.2020.4.13

Рыговский, Д. С. (2019) Енисейские и шорские староверы: сложная структура «простого» сообщества // Новые исследования Тувы. № 1. С. 60-74. DOI: https://doi.org/10.25178/nit.2019.1.5

Селищев, А. М. (1920) Забайкальские старообрядцы: Семейские. Иркутск : Гос. Иркутский ун-т. 81 с.

Соловьев, Н. Ф. (1993) Знаменный распев // Христианство: Энциклопедический словарь : в 2-х т. М. : Большая Российская энциклопедия. Т. 1. 863 с. С. 561.

Стахеева, Н. Н. (1998) Старообрядчество в Восточной Сибири в XVII - начале XX вв. : автореф. дисс. ... к. ист. н. Иркутск. 30 с.

Стороженко, А. А. (2004) Старообрядчество Тувы во второй половине XIX - первой четверти XX вв. : автореф. дисс.... к. ист. н. Кызыл. 23 с. 
Стороженко, А. А. (2019) Старообрядческие монастыри «енисейского меридиана» в XX веке: истоки, традиции и современное состояние // Новые исследования Тувы. № 1. С. 4-15. DOI: https://doi.org/10.25178/nit.2019.1.1

Татаринцева, М. П. (2006) Старообрядцы в Туве: Историко-этнографический очерк. Новосибирск : Наука. 216 с.

Татаринцева, М. П. (2019) Фольклор старообрядцев таежных деревень верховья Енисея в репертуаре детского ансамбля «Октай» // Новые исследования Тувы. № 1. С. 108-120. DOI: https://doi.org/10.25178/nit.2019.1.8

Татаринцева, М. П., Моллеров, Н. М. (2016) Русские в Туве (конец XIX - первая половина XX в.): История. Этнография. Культура. Новосибирск : Наука. 296 с.

Татаринцева, М. П., Стороженко, А. А. (2015) Старообрядцы Тувы: ретроспектива и современность. Saarbrucken: Lamber Academic Publishing. 137 c.

Урало-сибирский патерик: тексты и комментарии (2014-2016) : в 3-х т. / отв. ред. Н. Н. Покровский. М. : Языки славянской культуры ; Издательский Дом ЯСК. Кн. 1 (Т. 1-2). 462 с. Кн. 2 (Т. 3$) 296$ с.

Этнография старообрядцев Тувы (2014) [Электронный диск] : комплексная библиографическая и полнотекстовая база данных / сост. Н. Х. Наныкпан и др. Кызыл : Министерство культуры Республики Тыва, ГБУ «Национальная библиотека им. А. С. Пушкина Республики Тыва». 1 электрон. опт. диск (CD-ROM); 12 см.

Дата поступления: 28.05.2021 2.

\section{REFERENCES}

Bakhtina, O. N. (1999) Staroobriadcheskaia literatura i traditsii khristianskogo ponimaniia slova [Old Believer literature and traditions of the Christian understanding of the word]. Tomsk, Tomsk University Publishing House. 261 p. (In Russ.).

Buraeva, S. V. (2018) Staroobriadcheskaia knizhnaia traditsiia Eniseia: vozmozhnosti i problemy komparativnogo analiza [The old believers' book tradition of the Yenisei: the challenges and opportunities of comparative analysis]. Vestnik Vostochno-Sibirskogo gosudarstvennogo instituta kul'tury, no. 4 (8), pp. 29-38. (In Russ.). DOI: https://doi. org/10.31443/2541-8874-2018-4-8-29-38

Bykova, E. V. and Prigarin, A. A. (2019) Mir vizual'nykh obrazov staroobriadtsev Tuvy: ot ikony i lubochnoi kartinki do fotografii [The world of visual images of the Tuva Old Believers: from icons and popular prints to photos]. New Research of Tuva, no. 1, pp. 75-94. (In Russ.). DOI: https://doi.org/10.25178/nit.2019.1.6

Danilko, E. S. (2019) «Smert' blizhe rubashki»: pokhoronnaia obriadnost’ staroobriadtsev-chasovennykh [«Death is closer than a shirt»: Funeral ceremonialism of Chasovennye (“Chapel-going”) Old Believers]. New Research of Tuva, no. 1, pp. 44-59. (In Russ.). DOI: https://doi.org/10.25178/nit.2019.1.4

Dergacheva-Skop, E. I., Alekseev, V. N. (2003) Arkheograficheskie issledovaniia Sibiri vtoroi poloviny 60 - nachala 70-kh godov i formirovanie kollektsii rukopisnykh i staropechatnykh knig [Archeographic studies of Siberia in the second half of the 1960s and early 1970s and building a collection of handwritten and old-printed books]. In: Kniga i literatura $v$ kul'turnom kontekste [Book and literature in a cultural context]: a collection of articles / comp. and ed. by E. I. Dergacheva-Skop and V. N. Alekseev. Novosibirsk, RIO GPNTB SO RAN. 667 p. Pp. 23-36.

Dnevnik arkheograficheskoi gruppy N. N. Pokrovskogo 1967 g. [The 1967 field journal of Diary of N. N. Pokrovsky’s archeographic group] (2016). In: Uralo-Sibirskii Paterik: teksty i kommentarii [The Ural-Siberian Patericon: texts and commentary] (2014) : in 3 vols. / ed. by N. N. Pokrovsky. Moscow, Iazyki slavianskoi kul'tury. Book 2 (Vol. 3 ). 295 p. Pp. 153-193, 210-212.

Dutchak, E. E. (2019) Sibirskie staroobriadcheskie skity i ikh pastva na rubezhe 1920-1930-kh gg. [Siberian Old Believer Sketes and their parishioners between the 1920s and 1930s]. New Research of Tuva, no. 1, pp. 29-43. (In Russ.). DOI: https://doi.org/10.25178/nit.2019.1.3

Dukhovnaia literatura staroverov Vostoka Rossii XVIII-XX vv. [Spiritual literature of the Old Believers of the East of Russia of the 18th - 19th centuries] (1999) / ed. by N. N. Pokrovsky Novosibirsk, Sibirskii khronograf. 799 p.

Zhuravel', O. D. (2012) Literaturnoe tvorchestvo staroobriadtsev XVIII - nachala XXI v.: temy, problemy, poetika [Literary work of the Old Believers from the 18th to the beginning of the $21^{\text {st }}$ century: themes, problems, poetics]. Novosibirsk, Izdatel'stvo SO RAN. 442 p.

Zol'nikova, N. D. (2016) Dnevnik tuvinskoi arkheograficheskoi gruppy $1967 \mathrm{~g}$. kak istochnik po istorii staroveriia [1967 field journal of the Tuvan archeographic group as a source on the history of the Old Belief]. In: Uralo-Sibirskii paterik: teksty $i$ kommentarii [The Ural-Siberian Patericon: texts and commentary] (2014) : in 3 vols. / ed. by N. N. Pokrovskii. Moscow, Iazyki slavianskoi kul'tury. Book 2 (Vol. 3). 295 p. Pp. 270-277.

Ivanova, N. V. (2014) Leksicheskie reprezentatsii oppozitsii «svoi - chuzhoi» v dukhovnykh staroobriadcheskikh stikhakh [Lexical representations of the "friend - foe" binary opposition in spiritual verses by Old Believers]. Nauchnyi dialog, no. 12 (36): Philology, pp. 24-36.

Kostomarov, N. I. (1994) Istoriia raskola u raskol'nikov [The history of the schism among the schismatics]. In: Kostomarov N. I. Raskol. Istoricheskie monografii i issledovaniia [Schism. Historical monographs and research]. Moscow, Charli. 604 p. Pp. 265-327. 
Kostrov, A. V. and Morris, T. B. (2019) Vizual'no-tekstovaia agiografiia v nastennykh listakh sovremennykh staroobriadtsev chasovennogo soglasiia [Visuality and Textuality in Hagiographic Posters of Old Believers of the Chasovennye (“chapel-going”) Denomination]. New Research of Tuva, no. 1, pp. 95-107. (In Russ.). DOI: https://doi.org/10.25178/ nit.2019.1.7

Lamazhaa, Ch. K. (2018) Natsional'nyi kharakter tuvintsev [National character of Tuvans]. Moscow, St. Petersburg, Nestor-Istoriia. 240 p. (In Russ.)

Lipinskaia, V. A. and Leont'eva G. A. (2012) Deistvuiushchii travnik s lechebnikom: Pamiatnik staroobriadcheskoi pis'mennosti i narodnoi kul'tury sibiriakov [A herbalist with a book of cures: A monument of Old Believer writing and folk culture of the Siberians]. Moscow, In-t etnologii i antropologii RAN. 315 p. (In Russ.).

Liundup, T. V. (2019) Deiatel'nost' nauchnykh ekspeditsii v Tuve vo vtoroi polovine XIX - nachale XXI vv. [The work of research expeditions to Tuva from the second half of the $19^{\text {th }}$ to early $21^{\text {st }}$ centuries]: Abstract of Diss.... Candidate of History. Kyzyl. 21 p. (In Russ.).

Nikitina, S. E. (2017) «Svoe - chuzhoe» v iazyke i kul'ture russkikh konfessional'nykh grupp [The dichotomy of “Own” v. "alien" in the language and culture of Russian confessional groups]. Voprosy psikholingvistiki, no. 3 (33), pp. 76-91.

Obnovlenskii, A. P. (1993) Kormchaia kniga [The Rudder]. In: Khristianstvo: Entsiklopedicheskii slovar' [Christianity: An encyclopedic dictionary]: in 3 books. Moscow, Bol'shaia Rossiiskaia entsiklopediia. Vol. 1. 863 p. P. 828 . (In Russ.).

Pokrovskii, N. N. (1984) Puteshestvie za redkimi knigami [A journey for rare books]. Moscow, Kniga. 192 p. (In Russ.).

Pokrovskii, N. N. and Zol'nikova, N. D. (2002) Starovery-chasovennye na vostoke Rossii v XVIII-XX vv.: Problemy tvorchestva i obshchestvennogo soznaniia [Old Believers of the Chasovennoye accord in the East of Russia in the 18th - 20th centuries: Problems of creativity and public consciousness]. Moscow, Pamiatniki istoricheskoi mysli. 471 p. (In Russ.).

Pokrovskii, N. N. (2003) Iz istorii pervykh novosibirskikh arkheograficheskikh ekspeditsii [From the history of the first Novosibirsk archeographic expeditions]. In: Kniga i literatura $v$ kul'turnom kontekste [Book and literature in a cultural context]: a collection of research articles / comp. and ed. by E. I. Dergacheva-Skop and V. N. Alekseev. Novosibirsk, RIO GPNTB SO RAN. 667 p. Pp. 15-22. (In Russ.).

Pokrovskii, N. N. and Zol'nikova, N. D. (2016) «Chiudesnye sobytiia» tret'ego toma Paterika ["Wonderful events” of the third volume of Patericon]. In: Uralo-Sibirskii paterik: teksty i kommentarii [The Ural-Siberian Patericon: texts and commentary] (2014) : in 3 vols. / ed. by N. N. Pokrovskii. Moscow, Iazyki slavianskoi kul'tury. Book 2 (Vol. 3). 295 p. Pp. 213-269. (In Russ.).

Prigarin, A. A., Storozhenko, A. A. and Tatarintseva, M. P. (2020) Aktual'noe konfessional'noe pis'mo: mezhdu istoriografiei i biografiei (predvaritel'nye zamechaniia k rukopisi «Zapovednaia vera. Kniga zhitiia i stradanii symskikh staroobriadtsev»)[Contemporary confessional writing between historiography and biography: Preliminary notes on the manuscript "Sacred faith. The book of life and sufferings of the Old Believers of Sym")]. New Research of Tuva, no. 4, pp. 180-200. (In Russ.). DOI: www.doi.org/10.25178/nit.2020.4.13

Rygovskii, D. S. (2019) Eniseiskie i shorskie starovery: slozhnaia struktura «prostogo» soobshchestva [Old Believers of the Yenisei and Shoriya: a complex structure of a "simple" society]. New Research of Tuva, no. 1, pp. 60-74. (In Russ.). DOI: https://doi.org/10.25178/nit.2019.1.5

Selishchev, A. M. (1920) Zabaikal'skie staroobriadtsy: Semeiskie [Trans-Baikal Old Believers: the Semeyskye]. Irkutsk, Gos. Irkutskii un-t. 81 p. (In Russ.).

Solov'ev, N. F. (1993) Znamennyi raspev [Znamenny chant]. In: Khristianstvo: Entsiklopedicheskii slovar' [Christianity: An encyclopedic dictionary]: in 3 books. Moscow, Bol'shaia Rossiiskaia entsiklopediia. Vol. 1. 863 p. P. 561. (In Russ.).

Stakheeva, N. N. (1998) Staroobriadchestvo v Vostochnoi Sibiri v XVII - nachale XX vv. [Old Believers in Eastern Siberia in the $17^{\text {th }}$ - early $20^{\text {th }}$ centuries]: Abstract of Diss.... Candidate of History. Irkutsk. 30 p. (In Russ.).

Storozhenko, A. A. (2004) Staroobriadchestvo Tuvy vo vtoroi polovine XIX - pervoi chetverti XX vv. [The Old Believers of Tuva in the second half of the $19^{\text {th }}$ - first quarter of the $20^{\text {th }}$ centuries]: Abstract of Diss. ... Candidate of History. Kyzyl. $23 \mathrm{p}$. (In Russ.).

Storozhenko, A. A. (2019) Staroobriadcheskie monastyri «eniseiskogo meridiana» v XX veke: istoki, traditsii i sovremennoe sostoianie [Old Belief monasteries of the «Yenisei meridian» in the 20th century: origins, traditions and current state]. New Research of Tuva, no. 1, pp. 4-15. (In Russ.). DOI: https://doi.org/10.25178/nit.2019.1.1

Tatarintseva, M. P. (2006) Staroobriadtsy v Tuve: istoriko-etnograficheskii ocherk [Old believers in Tuva: a historical and ethnographic essay]. Novosibirsk, Nauka. 216 p. (In Russ.).

Tatarintseva, M. P. (2019) Fol'klor staroobriadtsev taezhnykh dereven' verkhov'ia Eniseia v repertuare detskogo ansamblia «Oktai» [The folklore of the Old Believers from the taiga villages of the Upper Yenisei in the repertoire of children's ensemble Oktai]. New Research of Tuva, no. 1, pp. 108-120. (In Russ.). DOI: https://doi.org/10.25178/nit.2019.1.8

Tatarintseva, M. P. and Mollerov, N. M. (2016) Russkie v Tuve (konets XIX - pervaia polovina XX v.) [Russians in Tuva in late 19th and the first half of 20th centuries]. Novosibirsk, Nauka. 295 p. (In Russ.). 
Tatarintseva, M. P. and Storozhenko, A. A. (2015) Staroobriadtsy Tuvy: retrospektiva i sovremennost' [The Old Believers of Tuva: the past and present]. Saarbrucken: Lambert Academic Publishing. 137 p. (In Russ.).

Uralo-Sibirskii paterik: teksty i kommentarii [The Ural-Siberian Patericon: texts and commentary] (2014) : in 3 vols. / ed. by N. N. Pokrovskii. Moscow, Iazyki slavianskoi kul'tury. Book 2 (Vol. 3). 296 p. (In Russ.).

Etnografiia staroobriadtsev Tuvy [Ethnography of the Old Believers of Tuva] (2014) : a comprehensive bibliographic and full-text database / comp. by N. H. Nanykpan et al. Kyzyl, Ministry of Culture of the Republic of Tyva, GBU "Pushkin National Library of the Republic of Tuva”. CD-ROM; $12 \mathrm{~cm}$.

Submission date: 28.05 .2021$. 